\title{
Multiorgan embolisation of a left ventricular thrombus
}

\author{
Derk Pol, ${ }^{1}$ Padeepa Perera, ${ }^{1}$ Sarah Zaman²
}

${ }^{1}$ Cardiology Department, Royal Melbourne Hospital, Parkville, Victoria, Australia

${ }^{2}$ Cardiology Department, Monash Heart - Monash Medical Centre, Clayton, Victoria, Australia

\section{Correspondence to}

Dr Padeepa Perera, padeepa.perera@gmail.com

Accepted 9 February 2019

\section{DESCRIPTION}

A 48-year-old man with T3N0 rectal adenocarcinoma status post an abdominoperineal resection and current adjuvant chemotherapy presented to the emergency department with chest pain for 2 days. His other medical comorbidities included hypertension, hyperlipidaemia, type 2 diabetes mellitus and previous deep venous thrombosis. His cardiovascular risk factors included smoking.

On presentation, ECG showed new deep T-wave inversion in the inferior limb leads, with a troponin I level at 28.4 (peak 35.0). Coronary angiography confirmed smooth coronary arteries and a large calibre-dominant left circumflex coronary artery with subacute near total thrombus occlusion of its obtuse marginal and posterior descending artery branches. The lesions were managed medically without percutaneous coronary intervention. A transthoracic echocardiogram (TTE) displayed a severely dilated left ventricle (LV) with moderately reduced ejection fraction due to infero-postero-lateral akinesis. It also exhibited a large $(2.0 \times 1.4 \mathrm{~cm})$, pedunculated, highly mobile mass attached to an akinetic segment of mid lateral LV wall (figure 1). Immediate anticoagulation was commenced for possible LV thrombus with therapeutic enoxaparin and warfarin loading.

For further characterisation of the LV mass and to assess for underlying malignancy, cardiac CT was performed the following day; however, the mass was no longer identifiable in the LV. Additionally, an immediate repeat TTE confirmed interval resolution of the $\mathrm{LV}$ mass, indicative of

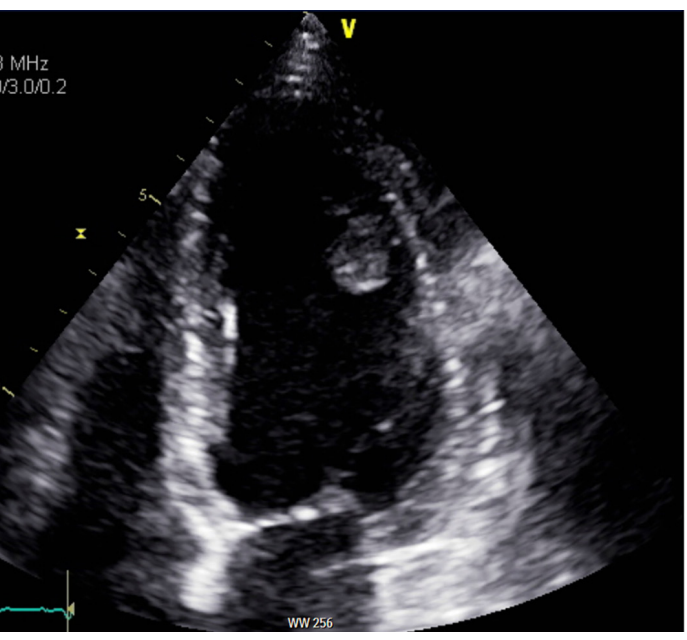

Figure 1 Transthoracic echocardiogram finding thrombus attached to an akinetic segment of the mid lateral left ventricular wall.

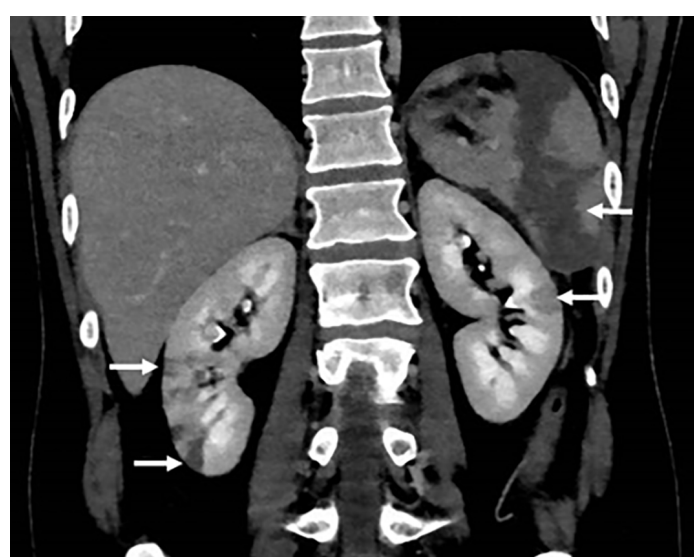

Figure 2 CT abdominal angiogram displaying multifocal embolic infarcts of the bilateral kidneys and spleen.

likely LV thrombus with subsequent complete embolisation. An urgent abdominal CT angiogram was then conducted investigating new abdominal discomfort symptoms, and this revealed multiple embolic infarcts (figure 2). This included multifocal infarcts of the bilateral kidneys, spleen and several loops of small intestine, and also portal venous thrombosis (segment VIII branch) with accompanying hepatic subcapsular wedge infarction. The peak venous lactate level was 2.3 , and low dose opioid analgesia was used. Marginally decreased protein $\mathrm{C}$ levels were identified on thrombophilia screening. He was subsequently discharged on warfarin with a repeat echocardiogram scheduled in 3 months.

Embolic sources from the LV can be thrombi (formed secondary to decreased LV systolic function and severe dyskinesis, akinesis or aneurysm of LV wall segments, or dilated cardiomyopathy with reduced systolic function) or non-thrombotic masses (including infectious or non-infectious vegetation or tumours). ${ }^{1}$

TTE is considered a first-line tool for the assessment of LV systolic function and identification of thrombi, and use of an endocardial contrast agent aids diagnostic accuracy. Cardiovascular magnetic resonance with gadolinium contrast is considered gold standard for LV thrombus diagnosis, if TTE is non-diagnostic. Thrombus protrusion and mobility are recognised as major echocardiographic risk factors for embolisation. Current literature identifies an embolisation risk of between $10 \%$ and $15 \%$ for untreated LV thrombus, with most events occurring within the first 3-4 months. ${ }^{12}$ 
Early anticoagulation with at least 3 months' duration is recommended after myocardial infarction in patients with documented LV thrombus and those with high risk for LV thrombus development/progression or embolisation. Follow-up imaging in 1-3 months is recommended to assess for thrombus progression or resolution, and to evaluate LV remodelling. ${ }^{13}$

\section{Learning points}

- Embolic sources from the left ventricle (LV) can be thrombi (formed secondary to an LV wall motion abnormality and reduced systolic function, or dilated cardiomyopathy with reduced systolic function) or non-thrombotic masses (including infectious or non-infectious vegetation or tumours).

- Thrombus protrusion and mobility have been identified as major echocardiographic risk factors for embolisation.

- Early anticoagulation with continuation for at least 3 months is recommended after myocardial infarction in patients with documented LV thrombus and those with high risk for LV thrombus development/progression or embolisation.
Key echocardiographic risk factors for embolisation of an LV thrombus include thrombus protrusion and mobility, and early anticoagulation is essential.

Contributors DP: Conception and planning, acquisition of information including obtaining patient consent, information verification and analysis, and write-up of the case report. PP: Acquisition of information including obtaining patient consent, literature review, design and write-up of the case report. SZ: Acquisition of information and analysis and verification of the information, supervision of the literature review and final write-up of the case report. Each author is in agreement to be accountable for all aspects of the work published.

Funding The authors have not declared a specific grant for this research from any funding agency in the public, commercial or not-for-profit sectors.

Competing interests None declared.

Patient consent for publication Obtained.

Provenance and peer review Not commissioned; externally peer reviewed.

\section{REFERENCES}

1 Gyh L, Manning WJ, Weissman NJ. Left ventricular thrombus after acute myocardial infarction [Internet]:UpToDate. 2018 https://www.uptodate.com/contents/leftventricular-thrombus-after-acute-myocardial-infarction

2 Stratton JR, Resnick AD. Increased embolic risk in patients with left ventricular thrombi. Circulation 1987;75:1004-11.

3 Vaitkus PT, Barnathan ES. Embolic potential, prevention and management of mural thrombus complicating anterior myocardial infarction: a meta-analysis. J Am Coll Cardiol 1993;22:1004-9.

Copyright 2019 BMJ Publishing Group. All rights reserved. For permission to reuse any of this content visit https://www.bmj.com/company/products-services/rights-and-licensing/permissions/

BMJ Case Report Fellows may re-use this article for personal use and teaching without any further permission.

Become a Fellow of BMJ Case Reports today and you can:

- Submit as many cases as you like

- Enjoy fast sympathetic peer review and rapid publication of accepted articles

- Access all the published articles

- Re-use any of the published material for personal use and teaching without further permission

For information on Institutional Fellowships contact consortiasales@bmjgroup.com

Visit casereports.bmj.com for more articles like this and to become a Fellow 